\title{
EVOLUÇÃO DO TAMANHO DE GRÃO AUSTENÍTICO DURANTE A LAMINAÇÃO DE TIRAS A QUENTE DE AÇOS MICROLIGADOS AO NIÓBIO
}

Antonio Augusto Gorni ${ }^{\prime}$

Marcos Roberto Soares da Silva '

\section{Resumo}

A ocorrência de recristalização dinâmica nas cadeiras intermediárias do Trem Acabador do Laminador de Tiras a Quente promove substancial amaciamento do material, fato que pode levar a problemas no controle do processo e até mesmo ao sucateamento do esboço. O objetivo deste trabalho foi identificar as condições potenciais onde esse fenômeno pode ocorrer, o que foi feito através da aplicação de um modelo matemático de evolução microestrutural. Constatou-se que, no caso específico da usina de Cubatão da Usiminas, esse fenômeno geralmente ocorre durante a laminação de bobinas a quente finas, com teor relativamente baixo de nióbio e sob temperaturas ligeiramente mais baixas do que as usuais.

Palavras-chave: Laminação de tiras a quente; Aços microligados; Evolução microestrutural; Recristalização dinâmica.

\section{EVOLUTION OF THE AUSTENITE GRAIN SIZE DURING HOT STRIP ROLLING OF NIOBIUM MICROALLOYED STEELS}

\begin{abstract}
The occurrence of dynamic recrystallization in the intermediate stands of the Finishing Mill of a Hot Strip Mill promotes substantial softening of the rolling stock, a situation that can cause operational problems and even scrapping of the strip. The aim of this work was to identify the specific process conditions that can lead to this situation, which was carried out through the application of a microstructural evolution model. It was verified, for the specific conditions of the Cubatão Works of Usiminas, that this problem generally occurs during the processing of thin hot coils, with a relatively low $\mathrm{Nb}$ content and under rolling temperatures slightly lower than the normal range.
\end{abstract}

Keywords: Hot strip rolling; Microalloyed steels; Microstructural evolution; Dynamic recrystallization.

\section{INTRODUÇÃO}

O conhecimento sobre a evolução microestrutural dos aços laminados a quente proporciona importantes benefícios em termos de um melhor controle de processo. Dessa forma é possível otimizar a composição química dos aços, reduzir a dispersão das características mecânicas e dimensionais do produto, minimizar os níveis de refugo e evitar a degradação da qualidade do material produzido [I].

Essas possibilidades de melhoria justificam os inúmeros estudos feitos nessa área ao longo das últimas décadas, bem como a intensa atividade que ainda se observa nos dias de hoje. Ainda há muito a ser compreendido, particularmente na laminação em escala industrial, onde as condições de processo são muito mais complexas e imperfeitas do que se pode obter em laboratório. Na laminação a quente industrial há a presença de gradientes de temperatura, grau e velocidade de deformação, e de composição química ao longo da espessura do laminado, desconhecimento sobre as condições reais na interface cilindro de trabalho-laminado e problemas para se coletar dados precisos e consistentes, o que dificulta o ajuste e aplicação de modelos teóricos ao controle de processo.

Ocorrências aparentemente inexplicáveis de sucateamento de bobinas de aços microligados durante seu processamento no Trem Acabador do Laminador de Tiras a Quente \# I da usina de Cubatão da Usiminas motivaram uma análise mais detalhada sobre suas condições metalúrgicas de processamento, uma vez que esses acidentes podem estar associados à ocorrência de recristalização dinâmica nas cadeiras intermediárias do Trem Acabador [2,3]. Essa situação justificou a proposição deste estudo sobre a evolução microestrutural dos aços microligados durante o processo de laminação de tiras a quente na usina de Cubatão e seu impacto na resistência à deformação a quente, de forma similar ao que já havia sido feito anteriormente para aços

'Usiminas, Cubatão, SP, Brasil. E-mail: antonio.gorni@usiminas.com 
ao C-Mn [4]. Seus reflexos sobre a resistência à deformação a quente dos aços microligados foram descritos em outro artigo [5].

\section{MATERIAIS E MÉTODOS}

O modelo para cálculo da evolução microestrutural durante a laminação de tiras a quente adotado neste trabalho foi desenvolvido por Siciliano [2,3]. Os dados de cada bobina laminada necessários para os cálculos desse modelo foram obtidos a partir de informações fornecidas pelo sistema supervisório do Laminador de Tiras a Quente \# I da usina de Cubatão da Usiminas. Infelizmente nem todos os dados metalúrgicos necessários encontravam-se disponíveis, o que levou à adoção de algumas premissas. Foi assumido que $\circ \mathrm{Nb}$ encontrava-se totalmente solubilizado após o reaquecimento da placa. $O$ tamanho de grão austenítico na entrada do Trem Acabador foi fixado em $80 \mu \mathrm{m}$, valor considerado típico para esboços de aço microligado após a laminação de desbaste. Considerou-se total ausência de recuperação entre passes consecutivos de laminação.

O cálculo do tamanho de grão ferrítico final foi feito em função do tamanho de grão austenítico e de seu grau de encruamento, usando-se as equações simplificadas citadas por Siciliano e Jonas [3] e assumindo-se taxa média de resfriamento de $10^{\circ} \mathrm{C} / \mathrm{s}$. Não foram considerados os efeitos da temperatura de bobinamento nem do resfriamento lento da bobina a quente sobre o tamanho de grão ferrítico.

Foram calculadas e analisadas as evoluções microestruturais de mais de 5.000 bobinas de aço microligado ao $\mathrm{Nb}$ processadas no Trem Acabador com seis cadeiras de laminação. Infelizmente ainda não há como medir o tamanho de grão austenítico real do esboço durante seu processamento industrial para se poder verificar os valores correspondentes calculados pelo modelo. Como alternativa foi feita uma comparação entre os valores experimentais de resistência à deformação a quente, determinados pelo modelo inverso de Sims a partir das cargas de laminação medidas, e os calculados por um modelo teórico que leva em conta o encruamento residual calculado pelo modelo microestrutural aqui adotado [5].

\section{RESULTADOS E DISCUSSÃO}

A maior parte dos casos analisados mostrou que as ocorrências de recristalização dinâmica durante o processamento de aços microligados no Trem Acabador se concentraram somente nas suas duas primeiras cadeiras. Tal tendência pode ser explicada ao se analisar a fórmula que determina o grau de deformação crítico para ocorrência da recristalização dinâmica [2,3], cujo valor diminui para maiores valores de temperatura e menores valores de taxa de deformação a quente, condições que predominam nessas cadeiras. Além disso, o grau de deformação nelas aplicado é relativamente alto e superior ao usado nas demais. Isso é válido principalmente no caso das bobinas mais finas, onde a redução total esboço/tira é maior, fazendo com que os passes aplicados nas cadeiras sejam mais pesados. Essa mesma situação já havia sido prevista anteriormente para bobinas a quente de aço ao C-Mn [4].

Sob tais condições o valor de resistência à deformação a quente eleva-se continuamente ao longo das cadeiras do Trem Acabador, não constituindo um problema mais sério para o controle automático do equipamento. Portanto, serão consideradas neste trabalho apenas as condições específicas de processo que levaram ao surgimento da recristalização dinâmica nas cadeiras intermediárias do Trem Acabador que, conforme já comentado acima, colocam a laminação em risco.

Dentro desse objetivo, primeiramente será analisado - caso de um par de bobinas a quente com mesmas dimensões e teores de nióbio, \# I A e \# I B, cujas evoluções microestruturais calculadas ao longo do Trem Acabador podem ser vistas na Figura I. Apesar de as duas bobinas apresentarem condições de processamento bastante parecidas, uma delas (\#IA) não apresentou recristalização dinâmica (DRX) durante sua passagem pelo Trem Acabador, enquanto que a outra (\#|B) apresentou recristalização dinâmica só na cadeira $F 3$, levando a um forte amaciamento na cadeira seguinte, conforme se pode observar na Figura 2. Note-se que o nível de acerto da previsão dos valores de resistência à deformação a quente baseada na evolução microestrutural
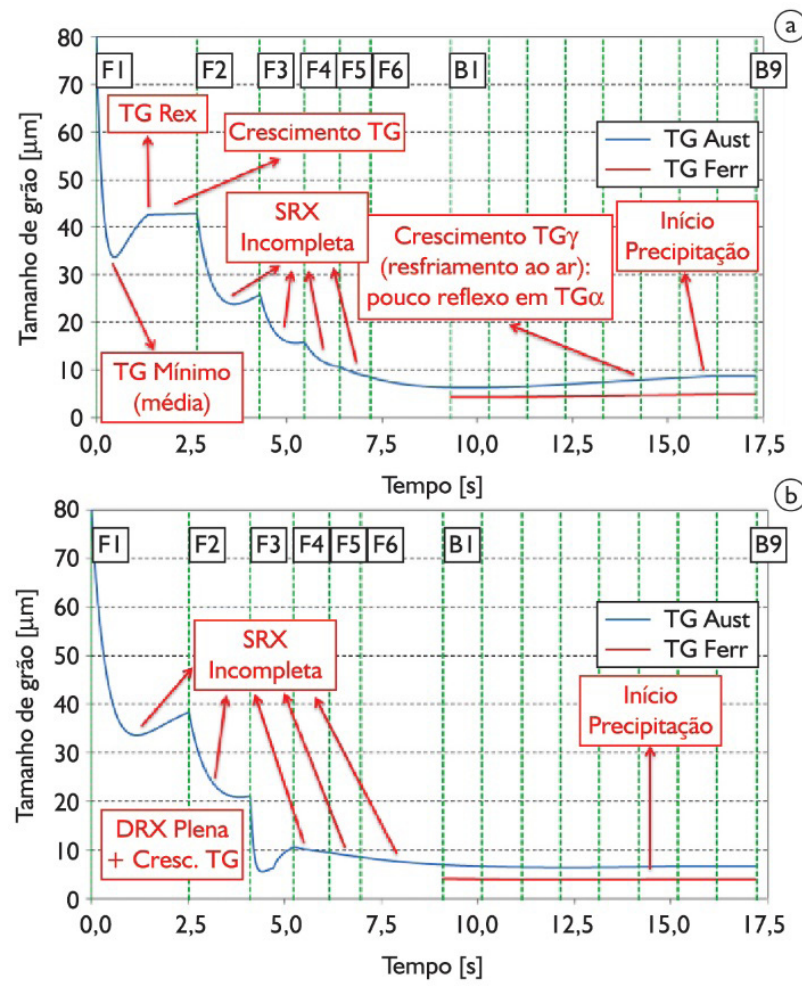

Figura I. Evoluções de tamanho de grão (TG) observadas ao longo do Trem Acabador para as bobinas (a) \# IA e (b) \# IB. 
foi razoavelmente bom nos dois casos, tendo apresentado erros de apenas 3,5\% e 9,3\% para as bobinas \# IA e \# IB, respectivamente.

A comparação entre os parâmetros de processo das bobinas \# I A e \# IB, apresentados na Tabela I, mostrou uma sutil diferença na evolução de temperaturas de laminação, que foram ligeiramente menores no último caso. Como se pode observar, a temperatura de laminação na $\mathrm{FI}$ da bobina \# I A foi igual a $995^{\circ} \mathrm{C}$. De acordo com o modelo de evolução microestrutural, essa condição promoveu a ocorrência de $100 \%$ de recristalização estática (SRX) mais crescimento de grão após o passe aplicado nessa cadeira, fazendo com que 0 esboço apresentasse encruamento residual nulo ao chegar à F2. A partir daí ocorreram somente recristalizações estáticas parciais após cada deformação nas cadeiras restantes. Sua cinética, apesar de incompleta, evitou um grau de encruamento residual mínimo para promover a ocorrência de recristalização dinâmica nas demais cadeiras. Assim sendo, a evolução da resistência à deformação a quente ao longo do Trem Acabador foi monotonicamente crescente no caso da bobina \# IA, conforme mostra a Figura 2a.
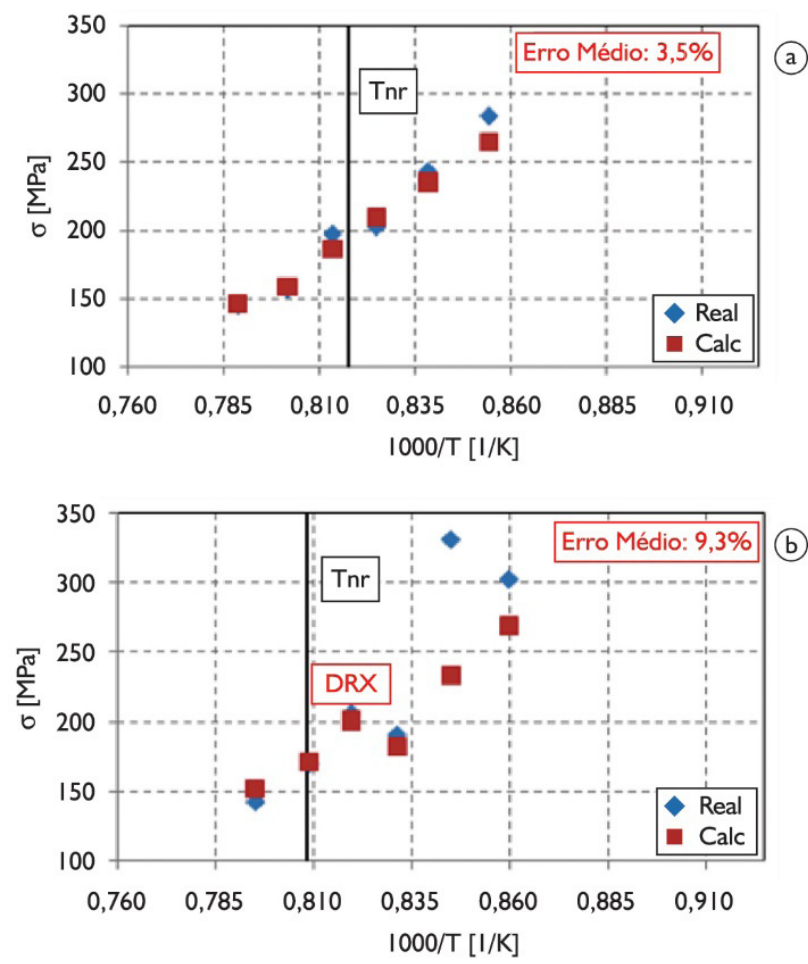

Figura 2. Evoluções de resistência à deformação a quente $(\sigma)$ observadas ao longo do Trem Acabador para as bobinas (a) \# I A e (b) \# IB.
Já a bobina \# IB foi laminada sob temperaturas ligeiramente inferiores, com temperatura na cadeira $\mathrm{FI}$ igual a $985^{\circ} \mathrm{C}$. Isso foi suficiente para restringir significativamente a cinética da recristalização estática após a deformação aplicada nessa cadeira e na seguinte. Essa condição levou a uma elevação progressiva do grau de encruamento residual do material até que ele chegasse ao nível suficiente para viabilizar a recristalização dinâmica na cadeira $F 3$. Este processo de restauração logrou eliminar totalmente o encruamento do material, o qual chegou à cadeira F4 não só totalmente recristalizado como tendo apresentado algum crescimento de grão. Em termos operacionais, isso se traduziu numa redução no valor da resistência à deformação a quente na cadeira F4, conforme mostrado na Figura $2 \mathrm{~b}$.

A Figura la ainda mostra que, imediatamente após a passagem do esboço \# IA pela cadeira $\mathrm{FI}$, seu tamanho de grão diminuiu progressivamente até atingir um mínimo, elevando-se acentuadamente a partir de então até atingir o valor correspondente ao término da recristalização do esboço. A seguir se iniciou a fase de crescimento de grão, em ritmo bem mais lento, que se prolongou até o laminado chegar à cadeira F2. Essa evolução típica do valor do tamanho de grão decorre de seu cálculo pela fórmula de Beynon e Sellars [6], que efetua uma média ponderada entre o tamanho de grão original e o recristalizado em função da evolução da fração recristalizada após o passe de laminação.

As menores temperaturas de laminação promoveram ligeiro refino de tamanho de grão austenítico na bobina \# IB em relação à \# IA. Contudo, de acordo com o modelo, o reflexo desse refino sobre o tamanho de grão ferrítico final foi virtualmente nulo. Além disso, nos dois casos, o modelo previu que a precipitação de compostos de $\mathrm{Nb}$ somente ocorrerá quando a tira já se encontrar fora do Trem Acabador.

Também podem ser feitas considerações interessantes ao se analisar os resultados relativos a outras duas bobinas a quente finas, \#2A e \#2B, similares às anteriores, mas cujos teores de $\mathrm{Nb}(0,014 \%$ e $0,015 \%$, respectivamente) foram ligeiramente menores do que os das duas bobinas analisadas anteriormente $(0,020 \%$ e $0,023 \%$, respectivamente para os casos \# I A e \# IB). As evoluções microestruturais relativas a esse segundo par de bobinas a quente podem ser vistas na Figura 3.

Da mesma forma como no caso anterior, as duas bobinas apresentam espessuras, composições químicas e condições de processamento bastante parecidas, mas uma delas, \#2A, apresentou recristalização dinâmica nas cadeiras $\mathrm{Fl}$ e F2. A outra, \#2B, apresentou recristalização dinâmica somente na cadeira $F 4$, levando conseqüentemente o esboço

Tabela I. Comparação entre composição química e parâmetros de processo relativos à laminação das bobinas \# IA e \# IB

\begin{tabular}{|c|c|c|c|c|c|c|c|c|c|c|c|c|c|c|c|c|}
\hline \multirow{3}{*}{ Caso } & \multicolumn{4}{|c|}{ Composição Química } & \multicolumn{6}{|c|}{ Graus de Deformação Real } & \multirow{2}{*}{\multicolumn{6}{|c|}{$\begin{array}{c}\text { Temperaturas } \\
{\left[{ }^{\circ} \mathrm{C}\right]}\end{array}$}} \\
\hline & \multicolumn{4}{|c|}{ [\%] } & \multirow[b]{2}{*}{ FI } & \multirow[b]{2}{*}{$\mathbf{F 2}$} & \multirow[b]{2}{*}{ F3 } & \multirow[b]{2}{*}{ F4 } & \multirow[b]{2}{*}{ F5 } & \multirow[b]{2}{*}{ F6 } & & & & & & \\
\hline & $\mathbf{C}$ & Mn & $\mathbf{S i}$ & $\mathbf{N b}$ & & & & & & & $\mathbf{F I}$ & $\mathbf{F 2}$ & $\mathbf{F 3}$ & $\mathbf{F 4}$ & $\mathbf{F 5}$ & F6 \\
\hline$\# I A$ & 0,08 & 0,41 & 0,06 & 0,020 & 0,77 & 0,58 & 0,48 & 0,37 & 0,23 & 0,14 & 995 & 974 & 956 & 939 & 930 & 897 \\
\hline$\# \mid B$ & 0,07 & 0,54 & 0,07 & 0,023 & 0,78 & 0,59 & 0,47 & 0,36 & 0,19 & 0,13 & 985 & 963 & 947 & 930 & 911 & 890 \\
\hline
\end{tabular}



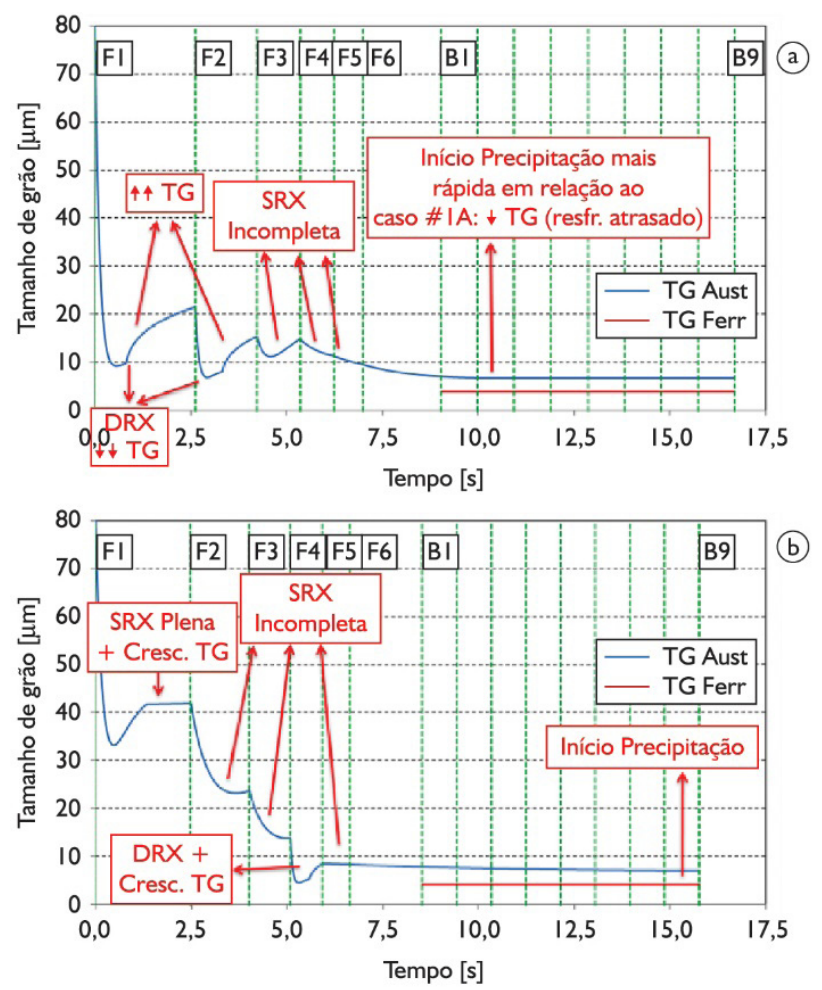

Figura 3. Evoluções de tamanho de grão observadas ao longo do Trem Acabador para as bobinas (a) \#2A e (b) \#2B.

a sofrer amaciamento na F5, conforme mostrado na Figura 4. Mais uma vez o grau de precisão na previsão da resistência à deformação a quente levando-se em consideração a evolução microestrutural foi bom, tendo alcançado erro médio de 4,3\% e 7,0\% para as bobinas \#2A e \#2B, respectivamente.

Novamente essa diferença na evolução microestrutural pode ser atribuída a uma sutil alteração na evolução das temperaturas ao longo da laminação dos dois materiais, a qual foi ligeiramente maior para a bobina \#2A, conforme mostra a Tabela 2. Nota-se, na Figura 3a, que o crescimento de grão calculado para a bobina \#2A após a ocorrência de recristalização dinâmica nas cadeiras FI e F2 foi muito maior em relação ao que se observa no caso da recristalização estática. É curioso constatar ainda que a bobina \#2A apresentou recristalização dinâmica nas cadeiras $\mathrm{FI}$ e $F 2$, enquanto que só se observou recristalização estática durante todo o processamento da bobina \# IA. Isso pode ser atribuído à sequência de temperaturas mais elevadas $\mathrm{e}$ o menor teor de $\mathrm{Nb}$ da bobina \#2A em relação à \# IA, a qual reduziu o valor da deformação crítica necessária para a deflagração da recristalização dinâmica, uma vez que os demais parâmetros de processo foram bastante similares entre essas duas bobinas. Já as bobinas \#2B e \# I B apresentaram sequências muito similares de graus de deformação e de temperatura ao longo do Trem Acabador.

Contudo, o menor teor de $\mathrm{Nb}$ da bobina \#2B favoreceu a ocorrência da recristalização estática, especialmente no caso da cadeira $\mathrm{FI}$, onde ela não só se completou como
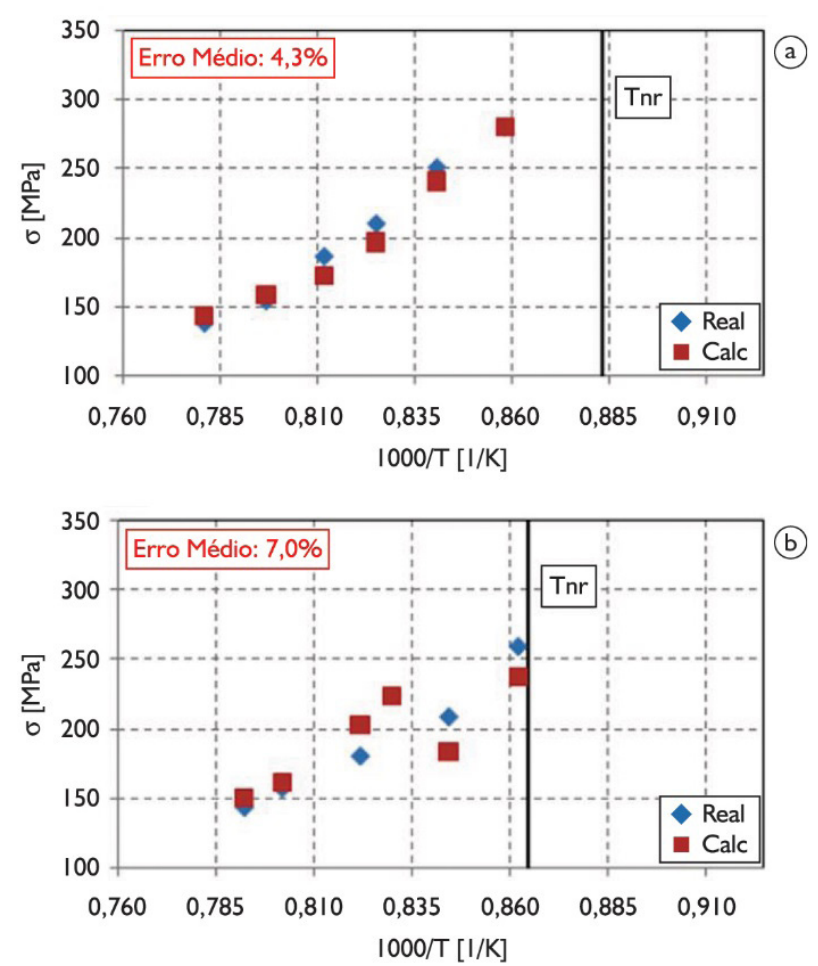

Figura 4. Evoluções de resistência à deformação a quente observadas ao longo do Trem Acabador para as bobinas \#2A e \#2B.

chegou a haver crescimento de grão, ao contrário do que havia sido constatado para a bobina \# IB. Isso reduziu a evolução do encruamento residual do esboço laminado, fazendo com que a ocorrência de recristalização dinâmica se atrasasse um pouco, passando da cadeira F3 (bobina \# IB) para F4 (bobina \#2B).

Portanto, o levantamento efetuado neste trabalho mostrou que, para as condições específicas do Laminador de Tiras a Quente \# I da usina de Cubatão da Usiminas, a recristalização dinâmica em cadeiras intermediárias do Trem Acabador somente ocorreu em casos bastante específicos envolvendo bobinas a quente leves, com espessura em torno de $2,3 \mathrm{~mm}$ a 2,6 $\mathrm{mm}$, teores relativamente baixos de $\mathrm{Nb}$, entre $0,014 \%$ e $0,023 \%$, e temperaturas de laminação ligeiramente mais baixas que as usuais.

Finalmente, é interessante analisar um terceiro caso, este relativo a uma bobina a quente pesada de aço microligado com espessura de $12,4 \mathrm{~mm}$ (\#3). A Figura 5a mostra a evolução microestrutural observada durante 0 processamento desse material no Trem Acabador, enquanto que a Figura $5 b$ mostra o bom grau de concordância obtido entre valores experimentais e calculados de resistência à deformação a quente, tendo sido observado erro médio de $8,4 \%$. Uma vez que a espessura do esboço na entrada do Trem Acabador é constante e relativamente independente da espessura final do produto, neste caso o grau total de redução aplicado ao esboço foi bem menor. 
Tabela 2. Comparação entre composição química e parâmetros de processo relativos à laminação das bobinas \#2A e \#2B

\begin{tabular}{|c|c|c|c|c|c|c|c|c|c|c|c|c|c|c|c|c|}
\hline \multirow{3}{*}{ Caso } & \multicolumn{5}{|c|}{ Composição Química } & \multicolumn{5}{|c|}{ Graus de Deformação Real } & \multirow{2}{*}{\multicolumn{6}{|c|}{$\begin{array}{c}\text { Temperaturas } \\
{\left[{ }^{\circ} \mathrm{C}\right]}\end{array}$}} \\
\hline & \multicolumn{4}{|c|}{ [\%] } & \multirow[b]{2}{*}{ FI } & \multirow[b]{2}{*}{$\mathbf{F 2}$} & \multirow[b]{2}{*}{ F3 } & \multirow[b]{2}{*}{ F4 } & \multirow[b]{2}{*}{ F5 } & \multirow[b]{2}{*}{ F6 } & & & & & & \\
\hline & C & Mn & $\mathbf{S i}$ & $\mathbf{N b}$ & & & & & & & $\mathbf{F I}$ & $\mathbf{F 2}$ & F3 & $\mathbf{F 4}$ & F5 & F6 \\
\hline$\# 2 \mathrm{~A}$ & 0,05 & 0,34 & 0,19 & 0,014 & 0,78 & 0,59 & 0,49 & 0,39 & 0,24 & 0,17 & 1008 & 982 & 959 & 939 & 916 & 892 \\
\hline$\# 2 B$ & 0,05 & 0,33 & 0,16 & 0,015 & 0,79 & 0,60 & 0,51 & 0,36 & 0,26 & 0,13 & 989 & 974 & 944 & 927 & 906 & 882 \\
\hline
\end{tabular}

Tabela 3. Composição química e parâmetros de processo relativos à laminação da bobina \#3

\begin{tabular}{|c|c|c|c|c|c|c|c|c|c|c|c|c|c|c|c|c|}
\hline \multirow{3}{*}{ Caso } & \multicolumn{4}{|c|}{ Composição Química } & \multicolumn{6}{|c|}{ Graus de Deformação Real } & \multirow{2}{*}{\multicolumn{6}{|c|}{$\begin{array}{c}\text { Temperaturas } \\
{\left[{ }^{\circ} \mathrm{C}\right]}\end{array}$}} \\
\hline & \multicolumn{4}{|c|}{$[\%]$} & \multirow[b]{2}{*}{$\mathbf{F I}$} & \multirow[b]{2}{*}{ F2 } & \multirow[b]{2}{*}{ F3 } & \multirow[b]{2}{*}{ F4 } & \multirow[b]{2}{*}{ F5 } & \multirow[b]{2}{*}{ F6 } & & & & & & \\
\hline & C & Mn & $\mathbf{S i}$ & $\mathbf{N b}$ & & & & & & & $\mathbf{F I}$ & F2 & F3 & F4 & F5 & F6 \\
\hline \#3 & 0,14 & 0,76 & 0,02 & 0,013 & 0,51 & 0,17 & 0,15 & 0,13 & - & 0,07 & 985 & 974 & 955 & 940 & - & 920 \\
\hline
\end{tabular}
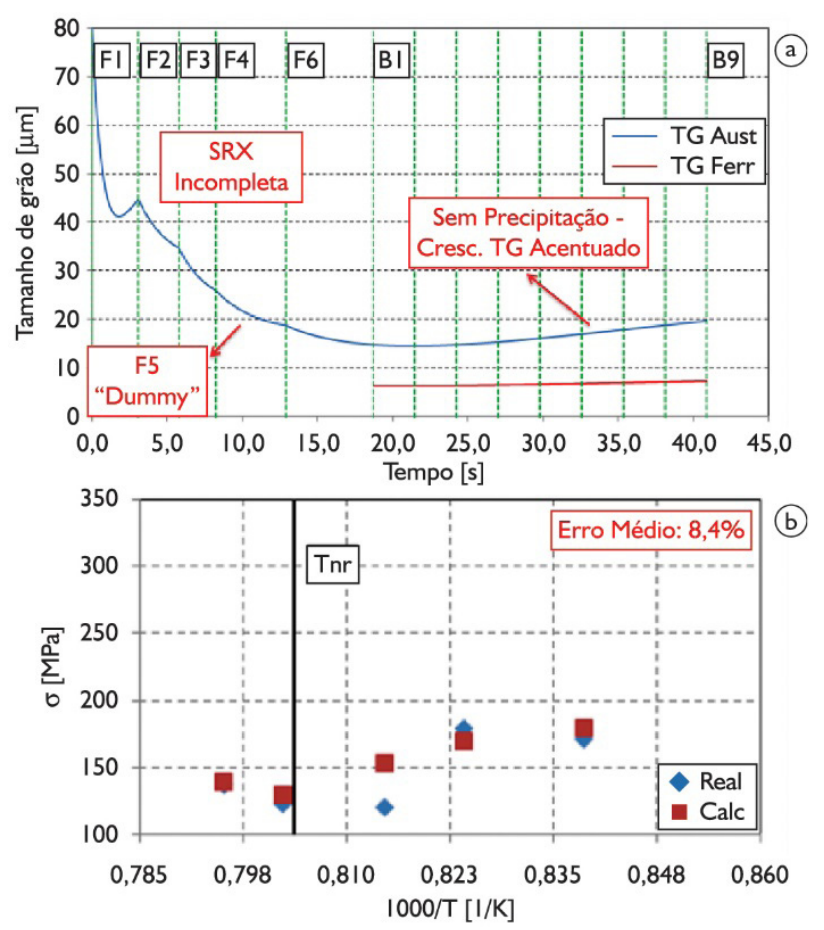

Figura 5. Evoluções ao longo do Trem Acabador observadas para a bobina \#3: (a) tamanho de grão; (b) resistência à deformação a quente.

Conforme se observa na Tabela 3, isso se refletiu no valor dos passes individuais, os quais foram bem menores do que os observados para os casos anteriores, apesar da cadeira $\mathrm{F} 5$ ter ficado ociosa durante o processamento desse material mais espesso. Os menores graus de deformação inviabilizaram a ocorrência de recristalização dinâmica e retardaram bastante a recristalização estática entre passes, o que levou a um significativo aumento no tamanho de grão austenítico que, entretanto, não se refletiu plenamente na ferrita transformada, de acordo com o modelo aqui adotado.

As análises feitas durante este trabalho, incluindo aquelas não apresentadas aqui, indicam que o tamanho de grão final da bobina a quente - tanto austenítico como ferrítico - depende muito pouco dos fenômenos de restauração específicos que tenham ocorrido, mas sim da deformação total esboço/tira aplicada no Trem Acabador. A recristalização dinâmica refina intensamente a microestrutura do material, mas esse efeito é momentâneo e virtualmente anulado pelo acentuado crescimento de grão subseqüente, como se pode observar na Figura 3a. De fato, na produção de bobinas a quente com tamanho de grão ultrafino, onde a recristalização dinâmica possui papel vital no refino microestrutural, o processo é conduzido de forma a promover sua ocorrência nas últimas cadeiras do Trem Acabador, mas evitando o crescimento de grão posterior através do resfriamento intensificado da tira e da redução do intervalo de tempo entre passes [7].

Os casos aqui analisados mostraram que mesmo pequenas diferenças nos parâmetros de processo - como o grau de deformação e temperatura do passe - podem ser suficientes para alterar significativamente os fenômenos previstos de restauração e toda a evolução microestrutural ocorrida ao longo do processo, com reflexos importantes sobre a evolução das cargas impostas às cadeiras. Esse fato demonstra claramente que a precisão e fidelidade dos dados industriais coletados pela instrumentação são vitais para a correta determinação teórica da evolução microestrutural que ocorre na tira. Isso é particularmente válido para o caso da temperatura, fator vital na definição da cinética dos processos metalúrgicos. Infelizmente, a medição ou cálculo desse parâmetro é particularmente difícil, seja pela imprecisão inerente aos seus sensores, que são bastante afetados pela presença de carepa, vapor e água sobre a tira, bem como pelo inevitável gradiente térmico que se forma através da espessura do laminado. As condições específicas da interface cilindro de trabalho-esboço também podem impor gradientes de grau e velocidade de deformação ao longo da espessura do material e alterar localmente os fenômenos microestruturais.

Outro fator de grande importância para os cálculos é o teor de $\mathrm{Nb}$ efetivamente solubilizado no material, cuja determinação precisa não foi possível neste caso devido à falta de conhecimento sobre as condições de reaquecimento da placa. Portanto, a precisão dos cálculos depende de forma vital de um acompanhamento preciso das condições da linha, desde o enfornamento da placa até o bobinamento da tira, bem como de um cálculo preciso dos parâmetros que não 
podem ser diretamente medidos - como, por exemplo, as temperaturas de laminação nas várias cadeiras do Trem Acabador. Além disso, o próprio modelo de evolução microestrutural precisa ser analisado com mais rigor, já que ele inclui muitas constantes empíricas, cujos valores precisam ser validados ou ajustados quando o algoritmo é aplicado para instalações e aços específicos.

\section{CONCLUSÕES}

Este trabalho relata os resultados da aplicação de um modelo matemático para cálculo da evolução microestrutural durante a laminação de tiras a quente de aços microligados para se identificar as condições sob as quais ocorre recristalização dinâmica nas cadeiras intermediárias do Trem Acabador. Essas situações estão associadas a um forte amaciamento do material quando ele passa pela cadeira seguinte, situação que não está prevista no sistema de controle do equipamento e que eventualmente pode provocar distúrbios operacionais. Dentro das atuais condições de processamento e do mix de produtos do Laminador de Tiras a Quente \#I da usina de Cubatão da Usiminas, tal situação foi detectada durante o processamento de bobinas finas, com teor de $\mathrm{Nb}$ relativamente baixo, e que foram processadas numa faixa de temperaturas ligeiramente menor do que a normal. A experiência decorrente da aplicação massiva do modelo também mostrou a necessidade de não só se dispor de todos os dados reais de processo, como também garantir a precisão e consistência das informações fornecidas ao modelo. O próprio algoritmo também precisa ser revisto e ajustado para as condições específicas da linha e das ligas nela processadas.

\section{REFERÊNCIAS}

I Gorni AA. Modelamento matemático da laminação: de ficção científica a ferramenta para a capacitação industrial. In: Associação Brasileira de Metalurgia e Materiais. Anais do $60^{\circ}$ Congresso Anual da ABM; 2005; Belo Horizonte, Brasil. São Paulo: ABM; 2005. p. 3894-3903.

2 Minami K, Siciliano F Jr, Maccagno TM, Jonas JJ. Mathematical modeling of mean flow stress during the hot strip rolling of Nb steels. ISIJ International. 1996;36(I2): I507-I5I5.

3 Siciliano F Jr, Jonas JJ. Mathematical modelling of the hot strip rolling of microalloyed Nb, multiply-alloyed Cr-Mo, and plain C-Mn steels. Metallurgical and Materials Transactions A: Physical Metallurgy and Materials Science. 2000;3IA(2):5II-530.

4 Gorni AA, Vallim PSS. Efeito da recristalização dinâmica na resistência à deformação de aços processados no laminador de tiras a quente. In: Associação Brasileira de Metalurgia e Materiais. Anais do $40^{\circ}$ Seminário de Laminação: Processos e Produtos Laminados e Revestidos; 2003; Vitória, Brasil. São Paulo: ABM; 2003. p. 480-488.

5 Gorni AA, Silva MRS. Modelamento da resistência à deformação durante a laminação de tiras a quente de aços microligados ao nióbio. In: Associação Brasileira de Metalurgia e Materiais. Anais do 49 Seminário de Laminação: Processos e Produtos Laminados e Revestidos; 2012; Vila Velha, Brasil. São Paulo: ABM; 2012. p. 672-68I.

6 Beynon JH, Sellars CM. Modelling microstructure and its effects during multipass hot rolling. ISIJ International. 1992;32(3):359-367.

7 Eto M, Sasaki T, Fukushima S, Shibahara T, Miyata K, Wakita M. Development of super short interval multi-pass rolling technology for ultra-fine-grained hot strip. La Révue de Metallurgie. 2006;103(7-8):319-325.

Recebido em: 30 Dez. 2014

Aceito em: 9 Fev. 2015 